\title{
Alloxan-induced diabetes alters rat common carotid artery response to adenosine
}

\author{
Miroslav Radenković ${ }^{*}$, Marko Stojanović1, Radmila Janković, Mirko Topalović ${ }^{1}$, Milica Stojiljković ${ }^{1}$ \\ From 18th Scientific Symposium of the Austrian Pharmacological Society (APHAR). Joint meeting with the \\ Croatian, Serbian and Slovenian Pharmacological Societies. \\ Graz, Austria. 20-21 September 2012
}

\section{Background}

It is well established that diabetes mellitus represents an important risk factor for endothelial dysfunction and associated cardiovascular events. Accordingly, vascular responsiveness of different isolated blood vessels was shown to be altered in experimental diabetes. The aim of this study was to investigate the effect of adenosine on intact or denuded isolated rat common carotid arteries obtained from healthy or diabetic rats.

\section{Methods}

The current study involved two groups of male Wistar rats (220-280 g): (1) healthy controls and (2) rats with alloxaninduced diabetes. Carotid arteries were extracted from rats, carefully dissected from surrounding tissue, cut into $4 \mathrm{~mm}$ long rings and placed in an organ bath. The endothelium was removed from some rings by gently rubbing the intimal surface with stainless steel wire. Apart from the pharmacological verification, the presence of endothelial cells was confirmed by histological evaluation on randomly selected preparations. Concentration-response curves for adenosine $(0.01-100 \mu \mathrm{M})$ were obtained in a cumulative fashion on serotonin-precontracted arteries.

\section{Results}

The adenosine-induced maximal relaxant response of rings with or without endothelium was similar in all investigated groups ( $p>0.05$ ), indicating an equi-effective action of adenosine irrespective of diabetes. The analysis of the median effective concentrations $\left(\mathrm{pEC}_{50}\right)$ showed that the response of intact or denuded vessels to adenosine was comparable but only within each group, thus confirming an endothelium-independent relaxation. On the other hand, the comparison of $\mathrm{pEC}_{50}$ values between healthy and diabetic animals showed a significant decrease of $\mathrm{pEC}_{50}$ $(\mathrm{p}<0.05)$ in rats with alloxan-induced diabetes, which was also accompanied by a matching rightward shift of the cumulative concentration-response curves for adenosine.

\section{Conclusions}

Adenosine induced endothelium-independent relaxation of the rat common carotid artery, with comparable pharmacological efficacy in all investigated groups, yet with reduced pharmacological potency in diabetic rats. This confirms the initial hypothesis that diabetes alters the response of the rat common carotid artery to adenosine.

\section{Author details}

'Institute of Pharmacology, Clinical Pharmacology and Toxicology, Medical Faculty, University of Belgrade, 11129 Belgrade, Serbia. ${ }^{2}$ Institute of

Pathology, Medical Faculty, University of Belgrade, 11000 Belgrade, Serbia.

Published: 17 September 2012

doi:10.1186/2050-6511-13-S1-A16

Cite this article as: Radenković et al:: Alloxan-induced diabetes alters rat common carotid artery response to adenosine. BMC Pharmacology and Toxicology 2012 13(Suppl 1):A16.

\footnotetext{
* Correspondence: mradenkovic@med.bg.ac.rs

'Institute of Pharmacology, Clinical Pharmacology and Toxicology, Medical

Faculty, University of Belgrade, 11129 Belgrade, Serbia

Full list of author information is available at the end of the article
}

C 2012 Radenković et al; licensee BioMed Central Ltd. This is an Open Access article distributed under the terms of the Creative 